\title{
Inclusive ideologies and passive performances: exploring masculinities and attitudes toward gay peers among boys in an elite youth football academy
}

\author{
Running heads: \\ Journal of Gender Studies \\ A. Adams and E. Kavanagh \\ Adams Adi a, \\ Kavanagh Emma a \\ ${ }^{a}$ Department of Sport and Physical Activity, Bournemouth University, Bournemouth, UK \\ *Corresponding author. Email: aadams1@bournemouth.ac.uk
}

Received 05 Apr 2017; Accepted 04 Oct 2017

(C) 2017 Informa UK Limited, trading as Taylor \& Francis Group

\begin{abstract}
Drawing on data generated from semi-structured, one-to-one interviews in 2012, this article focuses on the attitudinal disposition toward homosexuality of 12 English academy level football players aged 14-15. Results highlight the presence of progressive attitudes toward homosexuality even though some of the youth feel they lack the agency to contest homophobia when espoused in their schools. Using a blend of two dominating masculinities theories, we use these interviews to highlight that boys in this setting are best understood as a complex imbrication of inclusivity yet sociallypassive acceptance. We suggest that boys of this age are now primed for learning agency to contest the social marginalization of others.
\end{abstract}

\section{Keywords}

Inclusive masculinities

homosexuality

adolescent boys

football (soccer)

elite sports

youth academy

\section{Introduction}

This article explores the attitudes of English male adolescent youth academy ${ }^{1}$ football players toward homosexuality and gay peers: highlighting the inclusive ideologies (but also, sometimes, socially-passive performances) of an age group and context never before studied in tandem through an inclusive masculinities lens (Anderson, 2009, 2014). Despite some professional footballers in recent years being more vocal on the 'issue' of gay footballers, relatively little is known about the 'mood' and 'voice' of young (prospective) professional footballers. Previous scholarship has outlined the structure and operation of English football academies at older 16-18 year-old age groups (e.g. Brown \& Potrac, 2009 ; Manley, Palmer, \& Roderick, 2012; McGillivray, Fearn, \& McIntosh, 2005; Monk \& Russell, 2000 ) and the expression of masculinities and attitudes among academy footballers again, post-16-years-old, toward homosexuality, gay footballers and gay peers (e.g. Magrath, Anderson, \& Roberts, 2015; also see Magrath, 2016 ). However, research remains somewhat limited particularly among mid-adolescent boys (pre-16-years-old) in football academies. Research exploring English (male) professional football has consistently described its culture as being saturated with dominating and subordinating masculinities (e.g. Cushion \& Jones, 2006, 2014; Parker, 2001, 2006). However, some recent data on masculinities among academy $16-18$ yearold footballers in the South of England generated by Magrath et al. ( 2015 ) suggests a more progressive, inclusive turn.

Drawing on interview data with 22 young male participants, Magrath et al. ( 2015 ) note: 'Results are clear: among the 22 future athletes we interviewed, they are unbothered by the issue of gays in sport'. (p. 14). Magrath et al. suggest that their work points to an increasing inclusivity (Anderson, 2009, 2014) in the context of professional sports and is currently the only research to explore inclusive masculinities and attitudes toward homosexuality in the youth academy of a professional football club in England.

Building on Magrath et al.'s ( 2015 ) findings, in this paper, we explore masculinities by focusing on the attitudes toward homosexuality and gay peers among a group of academy footballers at West-Side football club (a pseudonym). Drawing on previous theoretical work in the fields of gender and masculinities (Anderson, 2009; Connell, 1987), we highlight some of the progressive, 'inclusive' (Anderson, 2009) attitudes toward homosexuality espoused by boys at West-Side, although we

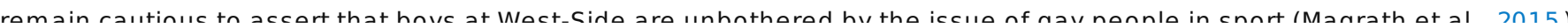


Findings point to contradictions in boys' performances of (inclusive) masculinities; that is, between boys' espoused inclusive attitudes and their own public performances of support for gay peers in their schools. In line with Roberts (2013), our findings therefore point to both change and continuity in the relations of young men in regard to traditionally hegemonic cultural ideals.

\section{Theorizing contemporary masculinities}

The work of Connell $(1987,1995)$ and Anderson $(2009,2014)$ has been adopted to inform the findings and analysis sections of this paper. Connell's seminal work on hegemonic masculinity, drawing on Gramsci's ( 1971 ) concept of hegemony, proposes that gender relations are hierarchical: a framework within which exists a plurality of ways of being a man, with particular (typically heterosexual) masculinities being more esteemed (hegemonic) and dominating other subordinated and marginalized masculinities, with others being complicit to and supporting this cultural organization of male bodies. Drawing on Connell's work, Messner (2002, p. 36, 37) has described the relationships between athletes in a homophobic, misogynistic environment in which athletes are either (1) 'leaders' (occupying an athletic centre and 'perpetuat[ing] misogynistic, homophobic assault[s] on the target' where the 'target' is a vulnerable, feminized object), (2) 'audience' or 'wannabe' boys who applaud and support the 'leaders', or (3) 'marginals' (lower status boys who support the misogyny and homophobia of leaders and wannabes through 'silent complicity').

Moving beyond Connell's $(1987,1995,2005)$ work on hegemonic masculinity describing the hierarchical relationships of men (with other men), and the relationships between men and women, Anderson $(2009,2014)$ has in recent years proposed and advanced a theory of inclusive masculinity, with others supporting this theoretical perspective (e.g. Adams, 2011 ; Adams \& Anderson, 2012; Anderson \& Adams, 2011 ; Cleland, 2014 ; Cleland, Magrath, \& Kian, 2016; McCormack, 2012; McCormack \& Anderson, 2014 ; Roberts, 2013 ). These scholars have described contexts in which multiple forms of masculinities proliferate with less hierarchy and no hegemony. Generally, this body of work suggests that Connell's hierarchical stratification of masculinities is failing to account for gender relations in contemporary society in which 'multiple masculinities [can] exist coharmoniously' (Anderson, 2011a, p. 254), with many young men in a variety of traditionally maledominated, hetero-masculine contexts (e.g. sports teams, fraternities) identified as opting to eschew the homophobic discourses and negativity toward gay peers that have previously characterized these cohorts.

In contrast to Connell's theorizing on hegemonic masculinity and Messner's idea of a homophobic athletic centre, Anderson's inclusive masculinity theory has suggested that homophobia and homohysteria (the fear of being thought homosexual) are much less significant in men's lives today (also see Gottzén \& Kremer-Sadlik, 2012; McCormack, 2012; Roberts, 2013 ). This cultural change has encouraged inclusive masculinities to proliferate, allowing inclusive masculinities to challenge orthodox masculinities for distinction within particular social contexts.

Roberts (2013, p. 14) study of young men in the South-east of England, for example, has highlighted how contemporary working-class masculinities are becoming attenuated or softened, suggesting a shift away from traditional manifestations of 'being a man' and a sharing of the 'summit of the hierarchy of hegemonic relations at any one point'. This way of thinking about masculinities challenges Connell's use of hegemony theory to explain masculinities and gender-relations, a theoretical framework in which Connell $(2005$, p. 77 ) has noted that: 'At any given time, one form of masculinity rather than others is culturally exalted'. Countering this characterization of men's inter-relations in contemporary Western societies, Anderson ( 2009 , p. 8) suggests that: 'in cultures of diminished homohysteria, two dominant (but not dominating) forms of masculinity will exist: One conservative [orthodox] and one inclusive'.

Anderson ( 2009 ) proposes that young men today no longer construct their gendered identities (masculinities) in relation to homosexuality or subordinated subject positions, nor through intentional homophobic language (McCormack, Wignall, \& Morris, 2016 ). Through his research, Anderson (2009) suggests that contemporary masculinities have shifted considerably toward inclusivity, offering evidence that this is the case on a cultural level in both the United States (US) and United Kingdom (UK). Anderson's theorizing (2009), developed from hundreds of interviews and multiple ethnographies has provided an empirically-rich way of looking at masculinities in today's social world, critiquing the contemporary use of ideas and concepts (such as Connell's hegemonic masculinity) which may have become taken for granted (Moller, 2007).

Underscoring the contemporary utility of inclusive masculinity theory, Anderson's ideas have been drawn on in multiple contexts to identify changes in the ways that masculinities are organized, and the changing relationships between older 'more conservative' and newer 'more inclusive' masculinities (e.g. Adams, 2011 ; Adams \& Anderson, 2012; Adams, Anderson, \& McCormack, 2010; Anderson, 2009, 2011a, 2011b, 2014 ; Anderson \& Adams, 2011 ; Anderson \& McCormack, 2015; Cashmore \& Cleland, 2012; Channon \& Matthews, 2015; Magrath et al., 2015; McCormack, 2012; McCormack \& Anderson, 2014 ). In summary, research recognizes that a seismic shift has occurred related to sexual identities and homophobia over the past 40 years. While this includes those writing in the inclusive masculinity theory vein (most notably the work of Adams, Anderson, McCormack, Cleland and Magrath), this shift has also been documented by a number of other scholars (Dean, 2014 ; Ghaziani, 2014 ; Savin-Williams, 2005 ; Twenge, Sherman, \& Wells, 2016 ; Weeks, 2007 ): that is, decreasing homophobia appears to be a significant national and international trend. 


\section{Methodology \\ Participants}

West-Side Football Club (a pseudonym) is an English professional football club that provides a structured training programme, or 'academy', for approximately 100 boys aged nine to 18 years old. The purpose of the academy is to develop athletes capable of entering into the professional arena at the age of 18 . Data presented in this paper were derived from semi-structured interviews conducted in 2012 with 12 boys (aged 14- and 15 years old), from one age group team, registered to the youth academy at West-Side. Following institutional ethical approval of this project, access to the sample was obtained through the primary author who previously occupied a role as an academy football coach at the club. Being minors, participants were recruited for interviews through their parents and guardians. In initial communications with parents a university/institution contact number was provided allowing parents, if they wished, to follow-up on claims made about the research and its legitimacy. Parents spoke to their sons and ascertained participant consent to be interviewed, with parents then communicating this consent back to the first author. Participant assent was further confirmed directly prior to the interview being conducted. All boys interviewed identified as White British.

One-to-one interviews lasted approximately $90 \mathrm{~min}$ and took place in a venue chosen by the participants (agreed with parents/guardians), with parents and guardians present in a nearby space, affording the interview to be visible but also allowing for privacy in terms of interviewee responses. Prior to the interviews being conducted, all parents and participants agreed to the interviews being audio-recorded, with the understanding that interview data would not be shared. Parents and interviewees were notified that interview data would be anonymized when transcribed, and finally that audio-recordings would be kept secure and destroyed upon completion of transcription.

\section{Analysis}

The processes of data collection, analysis and interpretation in this research were not distinct, linear tasks, but were intertwined (Brown \& Potrac, 2009 ; Sparkes, 2000 ). Interview transcription began as soon as possible upon completion of the interviews, so that further interviews were conducted in light of the themes that had emerged from the previous interviews (Brown \& Potrac, 2009 ; Sparkes, 2000 ). Transcribing interviews and writing up the analysis included relistening to interviews and rereading transcripts multiple times, to facilitate the identification and connection of individual 'units' of data scattered across the data-set.

Individual units of data were grouped, compared, merged, divided and (re)constructed into 'themes' to allow more abstract, theoretical levels of analysis to take place and more embracing thematic categories to be 'coded' and organized: through this process new concepts, themes, and categories were 'inductively' generated from the data (Glaser $\&$ Strauss, 1967; Potrac \& Jones, 2009 ). Similar to the process described by Sparkes and Smith (2002, p. 266), analysis of data required constant 'reflection on and interpretation of alternative explanations and interpretations'. Facilitating a discussion of alternative explanations of the first author's initial interpretations, (anonymized) data and themes were shared with the second author, a critical academic friend, helping to 'guard against the filters' through which the first author interprets the world (Sparkes \& Smith, 2014 , p. 182). Ultimately, this critical friendship resulted in two data 'themes' being developed, with the final stage of analysis incorporating these themes into a suitably theoretical and empirical framework (Cushion $\&$ Jones, 2014 ). Drawing on a sociological perspective of change and continuity in contemporary masculinities (Roberts, 2013 ), two themes are presented: (1) Primed for change: the presence of pro-gay sentiment, and; (2) Continuity: passive performances of masculinity.

\section{Ref lexivit y}

During interviews, the semi-structured arrangement was adopted in order to create the opportunity for flexible, in-depth conversation (Brown \& Potrac, 2009). In addition, this approach was useful in untangling the first author's connections to institutional power: an aspect of the research process which can impact on the quality of interview data (cf. Richards $\&$ Emslie, 2000). As a previous coach at West-Side, the first author both drew on shared memories of his time at the academy to develop rapport and trust, while also communicating his dis-connection and distance from institutional power. In this respect, the first authors' own insiderness and commonality (Roderick, 2006 ), but also outsiderness, with the participants offered a mechanism through which to negotiate (not eliminate) adult-child and coach-athlete power differentials, to achieve a position of honest, trustworthy and 'friendly adult' (Fine, 1987). Of course, recognizing that perceived power differentials can influence the pattern of interviews with adolescent boys (Jachyra, Atkinson, \& Gibson, 2014 )-, \#we acknowledge, therefore, that other researchers with varying gender, social and physical capital, and disciplinary relationships with academy-situated boys may yield varying 'stories'.

\section{Results}

\section{Primed for change: the presence of pro-gay sentiment}

In this section, we highlight evidence of change in youth masculinities among the boys interviewed: that is, an engagement with inclusive ideologies (Anderson, 2009 ; Magrath et al., 2015; Roberts, 2013 ). This included evidence that not just gay identities but bisexual identities are being normalized by young males involved in this elite youth sport setting 
AQ1 (Anderson \& McCormack, 2016; Savin-Williams, 2005 ). In order to get a sense of boys' thoughts and feelings about homosexuality, interviews were approached with the intention of developing a discussion around their awareness of and familiarity (social contact) with gay peers, friends and family. In interviews, boys generally expressed an attitude of acceptance during the opening discussions about gay friends, family and peers, as one of the boys, George, notes:

Yeah, I know some gay people. And it don't bother me ... My cousin is bisexual and I got two people in my tutor group who are gay. And I got like one of my best mates his cousin is gay and I know him quite well ... It don't affect what I think of them at all, I just think of them as normal people. I knew them before I found out, well one of them I knew, who's a little older than me, he came out quite a while ago, but it doesn't make a difference with him at all being gay.

George's statement above points to an inclusive ideology and set of values, cultivated through a rich blend of social contact with family and acquaintances of varying sexual orientations. His acknowledgement of bisexuality emerged naturalistically, since it was not the focus of any particular question (with questions framed simplistically, albeit the authors recognize problematically, around attitudes toward 'gay people'). George's recognition of bisexuality as a legitimate sexuality offers supporting evidence of a growing awareness of bisexuality and expanded notions of sexuality among today's youth (Anderson \& McCormack, 2016; Savin-Williams, 2005). Highlighting this further, Will stated: ‘n our school we got two gay people, a lesbian and I think we got a bisexual as well'. In addition, Kyle notes: 'Two came out in Year 7, one boy and one bisexual girl. And another came out a few years after'. Supporting the contention of Anderson and McCormack (2016) that youth today are recognizing a multiplicity of sexual identities as legitimate, Kyle adds, 'It was a bit of a shock, cos we were only about 12 years old'.

The data suggests the school environment was a familiar location for meeting (or, at least, knowing about) lesbian, gay and bisexual (LGB) people: 'There's a few people in my friend's school that are gay, and one of my brother's friend's at uni is one of his closest friends, and is gay' (Jamie). When questioning Jamie further about his suggested acceptance of his gay peers and what he thought had shaped his attitudes toward gay people, he cites his parents' tolerant and accepting attitude:

They've not been 'Oh he's different stay a way from him' and all that, they've just been like 'he's the same as you, he's a normal person, he still acts the same, you can still talk the same,' and that it basically don't matter.

Further demonstrating that some boys have not just 'heard about' LGB people in their social networks, but have also engaged with some of their LGB peers, Alex recalled a number of details about the gay people he knows personally. Alex stated the age of his gay peers, how old they were when they came out, how one of the boys in his wider friendship group is gay and how they sometimes 'hang out' at friend's houses as part of a bigger social group, and socialize at parties together. Alex noted matter-of-factly: 'We all get on and we just get on with it'. Regarding his gay peers, Alex also commented that he has 'grown up with it all around him', and so it feels 'normal'. The fact that some of his peers are gay is something that he believed he has adapted to: 'They're normal to me'. Yet, Alex acknowledged that even though he had inclusive attitudes he had not talked about 'this stuff' (meaning his social relationships with gay peers) much with others, as 'It can be hard to find the right words sometimes, cos I don't wanna offend people'.

In a similar vein, Jamie noted: 'We've grown up with it [gay peers]'. In the interview with Jamie, as part of an interview strategy to elicit more in-depth discussions, the first author described his own limited opportunity to share social spaces with LGB peers during his formative years, and the fact that he did not meet any openly gay people, or really get to know any gay people, until beginning an undergraduate course at university in 2005 (already into his early twenties). This led to a familiar exchange (participant made a playful jibe) about the first authors' ‘old age'. Jamie stated: 'We're used to it all now - a lot has changed since you were our age'.

Through various friend and family relationships and acquaintances, several of these West-Side academy players have established an awareness of the presence of LGB persons in different aspects of their lives. Data presented here, suggests that familiarity and social contact also had the potential to shape boys' views on homosexuality. Reece, discussing a family friend who is gay, expressed how:

When you think of a gay person, you think the extreme, all soft and that. And you kind of realise, you know, they're not always like that, and I suppose that's what everyone thought, the stereotype, but he's quite masculine as well I suppose.

Here, Reece initially suggests a conflation of homosexuality and femininity. However, his comments also highlight the potential complexity of individual perspectives on gender and sexuality among some youth today. Recognizing that the conflation of being 'all soft' with being gay is, in his words, a 'stereotype', Reece recalibrates this world view to incorporate a

AQ2 more diverse perspective of how boys and men can 'do' gender (West \& Zimmerman, 1987); that is, that gay men can be 'quite masculine as well I suppose'.

The data provided strong evidence of inclusivity (Adams, 2011 ; Anderson, 2009 ; Magrath et al., 2015 ) through changing attitudes toward and acceptance of gay peers among the boys on this particular team and age group of players at West-Side football academy. Data also suggests that it is not just gay identities that are being accepted and normalized by these boys through everyday social contact, but instead a multiplicity of sexual identities. Importantly, while inclusivity was in 
evidence, boys' acceptance of gay peers and a multiplicity of sexual identities was entwined with other issues and discourses of orthodoxy (Anderson, 2009 ), passivity and complicity (Connell, 1987, 1995).

\section{Continuity: passive performances of masculinity}

A second theme derived from the data related to the continuity of orthodox-aligned performances of masculinity (Roberts, 2013 ): specifically, the self-disclosure of engagement in passive performances of masculinity when encountering masculine orthodoxy from peers. Some of the boys interviewed reported these issues regarding witnessed or discussed prejudice. These boys' talked about disagreeing with but also sometimes 'going along with' some of the less-inclusive and prejudiced discourses and behaviours of peers. The concepts of orthodox masculinity (Anderson, 2009) and complicit masculinities (Connell, 1987, 1995; also see Messner, 2002) are important here, in order to position these boys within a theoretical understanding of masculinities: their thoughts, feelings and ideologies fitting with notions of inclusive masculinity, while 'balancing' alongside passive behaviours in the face of orthodoxy. Jamie, for example, noted: 'I still know a lot of people around who still don't think it [being gay] is normal and it shouldn't happen and all that'. Elaborating on this, Jamie explains that one day in a religious studies class at school, the topic of (homo)sexuality was discussed:

A load of people were just in class saying 'Oh it's not normal and it shouldn't be like that,' and saying a male and female can produce a baby, and that's how it should be.

Jamie added that he personally disagreed with the statements made in class that day, although he did not say this to his classmates.

For me, it's like, if they love them, they love them. You can't help it can you, it's the way you feel, but a lot of people aren't as OK with it. It shouldn't be like that, a lot of people ... you should just have to deal with it, if you got a problem with it just keep it to yourself.

Jamie stated that he felt the ideas articulated by his peers in class that day were problematic; however, he did not feel he could speak up and challenge those around him: 'I dunno, it's difficult to argue sometimes, cos I don't know what to say'.

Similarly, there were other boys who described witnessing homophobic attitudes and experiencing a clash with their personal beliefs and those of peers. One of those boys, Connor, described knowing two openly gay students at his school. 'I think it's fine ... You should be with who you wanna be with ... people are the way they are so let them be that way'. Continuing, he adds: 'People should feel comfortable in themselves, not hiding something from themselves or from someone else'. Referring back to the two gay students he is aware of in his school, Connor remarks on how they are treated by his peers: 'They get a bit of stick, not from me but they do get it. I just stay out of it'. When asked by the first author what he meant by this, Connor added: 'Like, people say stuff, jokes behind their back'. Connor says he did not contest these 'jokes', but instead decided to go along with them. He adds: 'I feel bad sometimes, like what l'd want to do sitting here now and say if it happened earlier in the day l'd think oh why didn't I say something'. The extract is highly instructive as it illustrates feelings of diminished agency among some of the boys in this setting to speak out concerning issues they actually viewed as problematic and believed should be challenged. This data highlights that inclusive ideology can remain in-tact despite prejudiced discourses and actions of peers, yet the impact of peer pressure is notable in that it served to suppress agency to promote inclusivity.

A similar admission of passivity in the face of witnessed prejudice by peers was made by Alex, somewhat in tension with his earlier claims about the inclusive practices among his friends and gay peers from his school (in previous findings section of this paper). 'That gay lad I told you about', says Alex, 'is in the group, but he's not'. Explaining in more detail, Alex notes:

Well I'm not best friends with him but he'd be at parties and stuff. It was a shock to hear about them [peers in school coming out as gay], and some people were going and taking the mick, and you know I went along a little bit, but I never, I wasn't doing it but I suppose I wasn't stopping it.

On one hand, Alex provides a statement of inclusive thinking (recounted earlier in this paper), yet his acknowledgement of homo-negative behaviour from his peers are interwoven with a lack of agency to challenge his friends from 'taking the mick' out of his gay peers. It was not clear from the data whether this meant that his friends were engaged in this behaviour in the presence of gay peers or 'behind their back' (as Connor described earlier), yet Alex felt that, while going 'along a little bit', he felt like he was performing a balancing act of masculinities, 'in the middle ... not sure what to say or do'.

In a similar line of discussion with Jack, in which we discuss why there are no gay footballers currently and the possibility of competing alongside or against gay teammates and opponents in the future, he notes: 'If gay people think they're not accepted then they might not play. If straight people show that they are accepted then more people might feel they can play, and then feel like they can be open'. However, a caveat to Jack's supportive (inclusive, pro-gay) attitude toward gay football players, is that he shows little desire at the prospect of publicly showing his support, thus revealing an ideologically inclusive and resistant yet behaviourally passive and docile expression of masculinity: ‘Personally I wouldn't say anything [pro-gay, to friends or teammates], but I think that it's good they do, like straight people saying that they accept gay people, takes a lot to say that'.

In other words. the inclusive thinkina of hovs like lack. mav remain concealed amona neers. Borrowina from Connell 


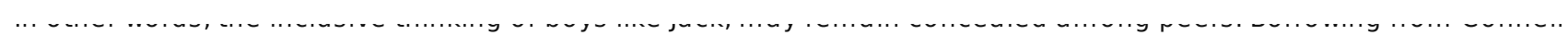

(1995), when confronted with more orthodox masculine practices in the stories they told, some boys' inclusive values were dormant rather than 'activated' during social encounters in their everyday lives. In their words, they were not sure what to say or do. Importantly, others have argued that intent is an important consideration in judging the 'homo-negativity' in boys' use of 'homophobic' language (McCormack et al., 2016). Interpreting our data along the contours of 'intent', the stories told by these boys suggest they experienced uneasiness with the language being used by peers. Revealed in these encounters is an intention by some boys' to 'take the mick' out of gay peers (p. 11): in the encounters described, 'homo-negative' ways of thinking and acting (despite making the boys in our study 'feel bad', p. 11) remained mostly uncontested.

Accordingly, there was evidence to suggest that some boys felt that the act of demonstrating their inclusivity, that is, calling out and contesting homo-negative or homophobic language and behaviour, had the potential to alienate them from their friendship groups. Highlighting how inclusivity can be suppressed in everyday experiences, Connor says:

The way I see it, taking the mick out of a gay person would just be like, it's not on ... but in school you're just trying to be the big man, show off in front of people, and make people laugh.

If Connor's claims to inclusivity are held to be true, his statement suggests, perhaps, that 'stepping in' and making public one's own inclusivity and acceptance was out-of-sync with the prevailing cultural masculinity of his school-based friendship group, i.e. of 'being the big man', 'showing off' and 'having a laugh'. In this instance, these cultural/contextual markers outweighed Connor's agency to uphold his own personal values of inclusivity. Such behaviour could also be reflective of wider societal behaviour where even adults can lack agency to stand up in situations of prejudice. Given Magrath et al.'s ( 2015 ) findings of inclusivity among 16-18 year-old academy footballers on the cusp of the professional game, it may be that Connor's inclusivity flourishes in the coming years as he enters into young adulthood.

It may well be that Connor and other boys in this study develop the agency which will enable them to challenge the homo-negativity of their peers; however, we cannot assume that this will happen. As the data presented demonstrate, the malleable nature of individual identities at this critical age can make individuals susceptible to peer pressure and the 'acting out' of the views of dominant group members rather than articulating their own value beliefs. This suggests that more needs to be done in order to progress inclusive attitudes in this setting to ensure they are less transient.

\section{Discussion}

This research explores attitudes toward homosexuality among boys in an English professional football academy, illustrating a complex account of boyhood masculinities: our findings tell a story of change and continuity in boys' performances of masculinities (Roberts, 2013 ). Building on Magrath et al.'s (2015) study of inclusive masculinities among youth footballers, this paper adds to the growing body of research focused on the transformation and movement of (young, straight, white) masculinities toward inclusivity (Anderson, 2009 ). In Magrath et al.'s ( 2015 ) qualitative research of 22 young professional footballers, the authors found that the young men in their study represented inclusive masculinities; that is, they showed a growing acceptance of homosexuality, suggestive of a rise in inclusive ideology within the younger ranks of the professional football industry. Similarly, we found attitudes of inclusivity, acceptance of homosexuality and a recognition of a multiplicity of legitimate sexual identities were present and formed through boys' social contact and familiarity with gay, lesbian and bisexual peers, friends and family.

However, describing the masculinities of these boys as simply inclusive or headed in a linear fashion toward inclusivity also remains problematic. Critical analysis of this data also revealed how inclusive ideologies remained entwined with a lack of agency in the face of homophobia: that is, acceptance of gay peers was coupled with boys' own self-disclosed examples of their inability to challenge the homo-negative talk of their peers. The interview excerpt from Jack (p. 12) - in which he described how it is good that straight people stand up for gay people, but personally he wouldn't say anything - is indicative of the limited 'strength' of many boys' ability to publicly express their inclusive values and to challenge orthodox discourses and practices. Although we remain encouraged by the data presented in its demonstration of the potential for transformative, socially-performed inclusivity to emerge as players potentially progress into professional careers ${ }^{2}$ we are mindful that this finding is matched with a discourse of passive performances surrounding homosexuality articulated by this sample.

This paper, therefore, offers evidence for the presence of inclusive ideologies among boys in one adolescent age group of a professional football club academy. Inclusive beliefs as expressed in interviews did not always mean that these boys were active in their expression or defence of inclusive values. The evidence presented here, suggests that silence and being passive in the face of homo-negative language from friends toward gay peers remains normative among these boys from West-Side academy. In this regard, findings are comparable with the work of Anderson ( 2009 ) and colleagues (e.g. Magrath et al., 2015), although we remain cautious in describing the performed masculinities found at West-Side among this particular group of boys as totally inclusive. Instead, we reinforce the transient nature of inclusivity and the malleability of attitudes found in this age group.

In light of the findings presented in this paper, a key challenge for individuals engaging with boys in this age group (e.g.

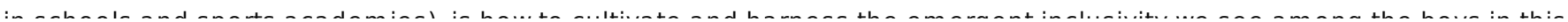




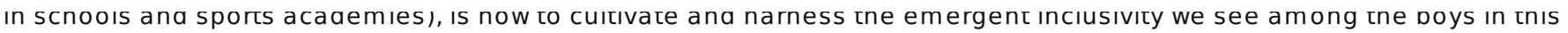
study, and how to equip boys with the agency to defend anyone from any marginalized group. Findings suggest significant potential for working with this 'strong but silent' population toward transformational behaviours of inclusivity consistent with attitudinal responses. Non-threatening education and reflection activities surrounding the nexus between sexualities, masculinities and equity issues in football potentially offers a platform for discussion critical in promoting change.

\section{Notes on contributors}

Adi Adams is a lecturer in Sport, Physical Activity and Coaching Sciences at Bournemouth University. His research is located in the discipline of sociology: previous research has been focused on gender, masculinities, sexuality, youth and sport.

Emma Kavanagh is a lecturer in Sports Psychology and Coaching Sciences at Bournemouth University. Her research interests are within the academic disciplines of psychology and sociology with current projects examining issues related to high-performance sport environments, such as humanization and dehumanization, athlete well-being, virtual and face-toface maltreatment.

\section{Disclosure statement}

AQ3 No potential conflict of interest was reported by the authors.

\section{Notes}

1.An 'academy' is a private, non-school-based, youth development programme for boys linked to a professional football (soccer) club. the primary objective of an academy is to produce young players for the professional, adult, 'first' team of a football club (see Bourke, 2003 ; Holt \& Mitchell, 2006 ; Relvas, Littlewood, Nesti, Gilbourne, \& Richardson, 2010 ).

2.To the authors' knowledge at least four of the boys who participated in this study are now active as adult professional footballers either at West-Side or other football clubs, while some are active at the semi-professional levels.

\section{Ref erences}

Adams , A. (2011). Josh wears pink cleats: Inclusive masculinity on the soccer field. Journal of Homosexuality, 58(5), 579-596.

\section{AQ 4}

Adams, A. , \& Anderson, E. (2012). Homosexuality and sport: Exploring the influence of coming out to the teammates of a small, Midwestern Catholic college soccer team. Sport, Education and Society, 17(3), 347-363.

Adams, A. , Anderson, E. , \& McCormack, M. (2010). Establishing and challenging masculinity: The influence of gendered discourses in organized sport. Journal of Language and Social Psychology, 29(3), 278-300.

Anderson, E. (2009). Inclusive masculinity: The changing nature of masculinities. London: Routledge.

Anderson , E. (2011a). Updating the outcome: Gay athletes, straight teams, and coming out in educationally based sport teams. Gender \& Society, 25, 250-268.

Anderson , E. (2011b). The rise and fall of western hom ohysteria. Journal of feminist scholarship, 1, 80-94.

Anderson, E. (2014). 21st century jocks. London: Palgrave MacMillan.

Anderson , E. , \& Adams , A. (2011). 'Aren't we all a little bisexual?' The recognition of bisexuality in an unlikely place (team sport). Journal of Bisexuality, 11(1), 3-22.

Anderson , E. , \& McCormack , M. (2015). Cuddling and spooning: Heteromasculinity and homosocial tactility among studentathletes. Men and Masculinities, 18(2), 214-230.

Anderson, E., \& McCormack, M. (2016). Inclusive masculinity theory: overview, reflection and refinement. Journal of Gender Studies, $1-15$

Bourke, A. (2003). The dream of being a professional soccer player: Insights on career development options of young Irish players. Journal of sport and social issues, 27(4), 399-419.

Brown , G. , \& Potrac , P. (2009). 'You've not made the grade, son': De-selection and identity disruption in elite level youth 
Cashmore ,E. , \& Cleland, J. (2012). Fans, homophobia and masculinities in association football. British Journal of Sociology, 63, 370-387.

Channon , A. , \& Matthews , C. R. (2015). 'It is what it is': Masculinity, homosexuality, and inclusive discourse in mixed martial arts. Journal of Homosexuality, 62(7), 936-956.

Cleland, J. (2014). Association football and the representation of homosexuality by the print media: A case study of Anton Hysén. Journal of Homosexuality, 61(9), 1269-1287.

Cleland, J. , Magrath , R. , \& Kian, E. (2016). The internet as a site of decreasing cultural homophobia in association football: An online response by fans to the coming out of Thomas Hitlzsperger. Men and Masculinities. online first doi:10.1177/1097184X1666326

Connell, R. W. (1987). Gender and power: Society, the person and sexual politics. Stanford, CA: Stanford University Press.

Connell , R. W. (1995). Masculinities. Berkeley: University of California Press.

Connell , R. W. (2005). Masculinities (2nd ed.). Berkeley: University of California Press.

Cushion , C. J. , \& Jones, R. L. (2006). Power, discourse, and symbolic violence in professional youth soccer: The case of Albion football club. Sociology of Sport Journal, 23, 142-161.

Cushion, C. J. , \& Jones, R. L. (2014). A Bourdieusian analysis of cultural reproduction, socialisation and the 'hidden curriculum' in professional football. Sport, Education and Society, 19(3), 276-298.

Dean , J. J. (2014). Straights. New York, NY: NYU Press.

Fine, G. A. (1987). With the boys: Little league baseball and preadolescent culture. Chicago, IL: University of Chicago Press.

Ghaziani , A. (2014). There goes the gayborhood? Princeton, NJ: Princeton University Press.

Glaser , B. , \& Strauss , A. (1967). The discovery of grounded theory: Strategies for qualitative research. New York, NY: Aldine de Gruyter.

Gottzén , L. , \& Kremer-Sadlik ,T. (2012). Fatherhood and youth sports: A balancing act between care and expectations. Gender and Society, 26(4), 639-664.

Gramsci, A. (1971). Selections from the prison notebooks. New York, NY: International Publishers.

Holt , N. , \& Mitchell ,T. O. (2006). Talent development in English professional soccer. International Journal of Sport Psychology, $37,77-98$

Jachyra , P. , Atkinson , M. , \& Gibson , B. E. (2014). Gender performativity during interviews with adolescent boys. Qualitative Research in Sport, Exercise and Health, 6(4), 568-582.

Magrath , R. (2016). Inclusive masculinities in contemporary football: Men in the beautiful game. London: Routledge.

Magrath , R. , Anderson , E. , \& Roberts , S. (2015). On the door-step of equality: Attitudes toward gay athletes among academy-level footballers. International Review for the Sociology of Sport, 50(7), 804-821.

Manley , A. , Palmer , C. , \& Roderick , M. (2012). Disciplinary power, the oligopticon and rhizomatic surveillance in elite sports academies. Surveillance and Society, 10, 303-319. 
McCormack, M. , \& Anderson ,E. (2014). Homohysteria: Definitions, context and intersectionality. Sex Roles, 71(3-4), 152-158.

McCormack, M. , Wignall , L. , \& Morris , M. (2016). Gay guys using gay language: Friendship, shared values and the intentcontext-effect matrix. The British Journal of Sociology, 67(4), 747-767.

McGillivray, D. , Fearn , R. , \& Mclntosh , A. (2005). Caught up in and by the beautiful game: A case study of Scottish professional fo otballers. Journal of Sport and Social Issues, 29, 102-123.

Messner, M. A. (2002). Taking the field: Women, men and sports. Minneapolis, MN: University of Minnesota Press.

Moller, M. (2007). Exploiting patterns: A critique of hegemonic masculinity. Journal of Gender Studies, 16(3), 263-276.

Monk, D. , \& Russell , D. (2000). Training apprentices: Tradition versus modernity in the football industry. Soccer and Society, 1, 62-79.

Parker, A. (1996). Chasing the big time: Football apprenticeship in the 1990s (Unpublished PhD thesis). University of Warwick.

AQE

Parker, A. (2001). Soccer, servitude and sub-cultural identity: Football traineeship and masculine construction. Soccer $\&$ Society, 2(1), 59-80.

Parker, A. (2006). Lifelong learning to labour: Apprenticeship masculinity and communities of practice. British Educational Research Journal, 32(5), 687-701.

Potrac , P. , \& Jones, R. L. (2009). Micropolitical workings in semi-professional football. Sociology of Sport Journal, $29,557-577$.

Relvas, H. , Littlewood, M. , Nesti, M. , Gilbourne , D. , \& Richardson , D. (2010). Organizational structures and working practices in elite European professional football clubs: Understanding the relationship between youth and professional domains. European Sport Management Quarterly, 10(2), 165-187.

Richards , H. , \& Emslie , C. (2000). The 'doctor' of the 'girl from the university'? Considering the influence of professional roles on qualitative interviewing. Family Practice, 17(1), 71-75.

Roberts, S. (2013). Boys will be boys ... won't they? Change and continuities in contemporary young working-class masculinities. Sociology, 1-6.

Roderick, M. J. (2006). The work of professional football: A labour of love? London: Routledge.

Savin-Williams, R. C. (2005). The new gay teenager. Cambridge, MA: Harvard University Press.

Sparkes , A. C. (2000). Autoethnography and narratives of self: Reflections on criteria in action. Sociology of Sport Journal, 17, $21-43$.

Sparkes, A. C. \& \& Smith, B. (2002). Sport, spinal cord injury, embodied masculinities, and the dilemmas of narrative identity. Men and Masculinities, 4, 258-285.

Sparkes , A. C. , \& Smith , B. (2014). Qualitative research methods in sport, exercise and health: From process to product. London: Routledge.

Twenge, J. M. , Sherman, R. A. \& Wells, B. E. (2016). Changes in American adults' reported same-sex sexual experiences and attitudes, 1973-2014. Archives of Sexual Behavior, 1-18.

Weeks , J. (2007). The world we have won. London: Routledge.

West, C., \& Zimmerman, D. H. (1987). Doing gender. Gender \& Society, 1(2), 125-151. 
